\title{
The EOLES project
}

\author{
Engineering labs anywhere
}

\author{
André Vaz Fidalgo ${ }^{1}$, Manuel Gericota ${ }^{1}$, Denis Barataud ${ }^{2}$, Guillaume Andrieu ${ }^{2}$, Renaat De Craemer ${ }^{3}$, Mihai Cristea ${ }^{4}$, Abdelhalim \\ Benachenhou $^{5}$, Mohammed Ankrim ${ }^{6}$, Karim Bouchlaghem ${ }^{7}$, Paulo Ferreira ${ }^{1}$ \\ ${ }^{1}$ School of Engineering/Polytechnic Institute of Porto, Porto, Portugal \\ ${ }^{2}$ Université de Limoges, Limoges, France \\ ${ }^{3}$ KU Leuven University, Ostend, Belgium \\ ${ }^{4}$ University Politehnica of Bucharest, Bucharest, Romania \\ ${ }^{5}$ University of Mostaganem, Mostaganem, Algeria \\ ${ }^{6}$ University Cadi Ayad of Marrakech, Marrakech, Morroco \\ ${ }^{7}$ University of Kairouan, Kairouan, Tunisia
}

\begin{abstract}
Keywords-electronics; optics; embedded systems; e-learning; engineering; remote laboratories.
\end{abstract}

\section{THE EOLES PROJECT}

The EOLES (Electronics and Optics e-Learning for Embedded Systems) project is a 3-year joint project involving 15 institutions, four from Europe and eleven from the North African countries of Algeria, Morocco, and Tunisia, whose aim is to create a 3rd year Bachelor degree in Electronics and Optics for Embedded Systems. The project started in October 2012 and is scheduled to end in October 2015.

One of the biggest challenges to a full implementation of an e-learning course in engineering is the laboratories. They are unanimously recognized as essential in any engineering course. Contrary to the majority of engineering courses that force students to attend on-site hands-on labs sometime along the course, EOLES students will be able to perform their lab duties online. Indeed, the most innovative aspect of this project is precisely the implementation of a remote laboratory that will enable students to carry out remotely the practical works associated to each technical unit within the course.

The project is currently in its final steps of implementation, and the first students are about to be enrolled for the next school year 2014-15. Candidate students must already have the first two years of a university Bachelor program on a related area (corresponding to 120 European Transfer Credit Units (ECTU)). Despite being designed to meet the rules and educational objectives of the three North African countries involved in the project, any student from anywhere in the world may apply to be enrolled in the 3 rd year, providing that he/she fulfills the admission requirements. The course is in process of accreditation by the national authorities of those countries. This is, indeed, one of the first measures to guarantee its sustainability beyond project's official term by the end of the third semester of 2015. Furthermore, the first students to finish the course will do so before the end of the project, which will enable partners to follow up the first year of its implementation, to introduce any corrections/changes as

This project is funded by the European Commission, under contract number 530466-TEMPUS-1-2012-1-FR-TEMPUS-JPCR. needed and thus to ensure the smooth and successful completion of the project.

\section{E-LEARNING ENGINEERING COURSES}

During the last decade, many established Universities started offering undergraduate e-learning programs, in addition to their classic on-site programs, creating specific e-learning frameworks and adapting their traditional offer to be delivered remotely. At the same time, some more recent Universities, like The Open University founded in 1969 [1], only offer online undergraduate and postgraduate programs. In spite of that, some courses, like languages and engineering, require attendance at a residential school. Even though, while postgraduate level engineering programs awarding a final Certificate, Diploma or Master degree are easy to find, the undergraduate offer is restricted to no-engineering areas. The exception are the widely available fully online information and computer technology (ICT) undergraduate programs, since the same computer used by the students to follow an ICT program may be used to perform practical work in the field.

The reason why Master degrees in Electrical and Computer Engineering are often found online stems from the possibility of using sophisticated modeling tools, which are easily deployable over the Internet, to perform lab assignments. By the contrary, undergraduate degrees, to be successful, require students to be able to perform experimental work in subjects like physics, chemistry, mechanical and electrical machines, or digital and analogue electronics, for example. These require the remote access to experimental labs and real time interaction with real experimental setups, which is far more complex to implement.

Until recently, the only solution has been the use of blended learning solutions as described in [2]. In this particular case, the entire program is conducted online, with the exception of the lab classes. These have to be performed on campus and are usually concentrated by the semester's end. Other examples (from the many available) are the Bachelor of Science in Electrical Engineering at The University of North Dakota [3], or the Bachelor of Science in Engineering Technology: 
Electrical at The University of North Carolina at Charlotte [4]. Blended learning solutions, however, have obvious disadvantages. First, the student must have the necessary time and funds to travel and spend a few weeks a year in the University campus. Second, from a pedagogical point of view, there is no synchronization among theoretical, tutorial and lab classes, which creates difficulties to the normal learning process, postponing in a certain sense the correct understanding and assimilation of the different subjects.

\section{LAB WORK AND REMOTE LABS}

The absence of online undergraduate degree programs in Electrical and Computer Engineering is far more incomprehensible since it is possible to find in the specialized literature many examples of different labs for different areas of physics and electrical engineering [5-12], each one allowing different degrees of freedom in the configuration of the experiment by the remote user. However, their use has been restricted, operating mainly as a complement of on campus lab classes and not as a part of a full online undergraduate program.

The EOLES project partners have an extensive experience in the area of remote labs for electronics and optics acquired in previous projects. Their past experience was presented and published in several conferences and journals.

The LAB-EN-VI (LABoratoire d'ENseignement VIrtuel) described in [10] is a microwave and optical laboratory that enables the remote control of different practical experiments in microwave and optical fields allowing students anywhere to work with high cost equipment (Sources, analyzers, receivers, ...) in a safe way.

The project described in [11] aimed to apply the principles and possibilities of distance and e-learning to traditional course materials and also to lab sessions, including the use of the computer as virtual measurement instrument in the laboratory. Students using this alternative e-learning approach were awarded with 20 ECTUs if they successfully completed all the proposed works.

Another example is the RemotElectLab [12], a laboratory for the implementation of electronic circuits that replicate, in terms of resources, facilities and functionality, those existing in a real lab. This remote lab enables students to follow the same steps in each experiment that they would follow if doing it during a normal lab class. The lab is fully reusable and has the same degree of flexibility of a normal breadboard, accepting the same components, enabling the execution of the same circuit modifications and of the same measurements required by the experiments proposed during normal electronics classroom lab activities. The only exception is the initial setup, since it is impossible to have an infrastructure with an unlimited number of degrees of freedom able to cope with the infinite number of circuits that may be assembled in a breadboard.

The EOLES project tries to unite all this knowledge towards the objective of creating a fully online undergraduate program on Electrical and Computer Engineering, with emphasis in the area of Electronics and Optics for Embedded
Systems. In this first step, only the 3rd year of the Bachelor program is going fully online. In the medium term, the goal is to remotely offer the full Bachelor program.

\section{THE COURSE}

The main objective of the EOLES project is to create a fully online English-spoken 3rd year Bachelor degree in electronics and optics for embedded systems. The number of students graduating each year is expected to be between 30 and 40. The students enrolled in the EOLES curriculum will have to respect the following criteria:

- To have a minimum English level evaluated through a TOEIC or a TOEFL test or equivalent;

- To have access to an internet connection with enough quality of service to support videoconference classes;

- To have previously obtained 120 ECTUs in Physics, Electronics or similar studies of a university Bachelor program.

Classes will be based on an international Virtual Learning Environment (VLE) using a modern pedagogical approach (e-learning 2.0) through the creation of an educational social network [13] designed to be used daily by students and teachers with the aim of promoting interactivity among all participants. This VLE comprises:

- Synchronous tools (virtual classrooms);

- Asynchronous tools (screen casting, forums, wikis, chat, announcement, e-mail);

- A remote laboratory with last generation equipment and instrumentation;

- An application server giving access to professional software.

The use of an "educational social network" aims not only to give students a chance to be pro-active in their own education but also to counter the loss of motivation and their dropping out in isolated areas or if affected by logistic or financial difficulties. Furthermore, by encouraging collaboration it is expected an improvement in students' theoretical and practical skills and in their English language level, contributing to increase the number of highly qualified workers in the North African countries.

The course is designed as a specialization year, with a curriculum oriented towards the embedded systems domain. The curriculum program and the accreditation by the national authorities of the three North African countries participating in the project will allow graduated students to later apply for postgraduate degrees.

The curriculum is composed of mandatory and optional Technical Units (TU) divided in weeks with always two TUs running in parallel to ensure diversity of subjects and to fight monotony without overloading students. The optional TUs are preparatory TUs provided at the beginning of the course, in order to level out students' knowledge on critical topics electronics and optics. The mandatory TUs cover a broader list of topics, ranging from the more technical oriented, like 
mathematics, physics, analogue and digital electronics, embedded systems, optics, signal processing or power electronics, to those targeting soft skills, like technical English, management and communication techniques.

Since the main originality of the course is the possibility for students to access a remote laboratory to perform online practical works and consequently to acquire essential practical skills, each TU will have 4 to 6 practical experiments. Two types of experiments will be performed:

-Laboratorial experiments intended to monitor and control technical equipment at distance;

-Laboratorial experiments using professional software available in the application server or freely available from Internet.

Multi-user access will be encouraged to guarantee strong interaction among students during the training. The remote laboratory is expected to have a substantial learning impact as each student could repeat the same experiment several times and try different configurations in a controlled and safe environment.

The teachers involved in each TU were selected according to their field of expertise. The number of teachers per TU is limited to three, with at least one teacher from a European partner institution and one teacher from a North African partner institution to ensure an efficient collaborative work and knowledge transfer among partners, apart from helping on the official accreditation of the Bachelor program and on the recognition of the Bachelor degree in all the countries participating in the consortium.

The pedagogical committee formed within the EOLES project consortium is defining the exam rules and access terms in detail, with the objective of balancing individual and group work and implementing a continuous evaluation of students' achievements. According to the experience of partners already involved in e-learning, a particular attention will be paid to avoid cheating, a potential risk in full e-learning training environments.

To ensure the sustainability of the course, this needs to be assessed over time. The quality assessment will focus on the:

\section{-Bachelor program content; \\ -E-learning platform's ergonomics; \\ -Remote laboratory performance.}

All the actors directly involved in the curriculum (students, teachers, technical and administrative staffs) will be implicated in the different quality assessment processes. Using the social tools available in the VLE, a student association will be created and a student representative will be elected each year to animate the community and discuss course issues with the pedagogical team, contributing also to course assessment.

\section{THE EOLES REMOTE LABORATORY}

The most innovative aspect of the proposed course is the use of a remote laboratory that will allow students to perform online all the proposed practical experiments. A multi-user approach will allow a group of students to work and interact in real time over the same practical work.

Two types of practical works will be included in the remote laboratory:

- Real-time monitoring and control of technical equipment, with each piece of hardware equipment (function generator or oscilloscope for instance) connected to the internet. The user will access a web page to change the hardware configuration and will see the effect of its actions via the same web page or through a highdefinition camera when justifiable;

- Virtual practical works based on specific design and simulation software packages.

The VLE servers and the remote laboratories are located in only three different institutions (one in each North African partner country) in order to reduce maintenance and installation costs. The practical works will not be duplicated. All the experiments will be integrated on a single and unified EOLES laboratory that will be accessible $24 / 7$ by all partner institutions.

\section{WORK IN PROGRESS}

The course syllabus was approved during the Second General Assembly of the EOLES project held in Kairouan, Tunisia, in the beginning of November 2013. The theoretical and practical course contents are now being created with the integration of all content, software and equipment schedule to be finished by May 2014 .

The EOLES laboratory is presently under development and will become operational by the middle of 2014 . The first students should begin using it in the autumn semester of 2014.

More information about the project may be found at the EOLES project web page: www.eoles.eu.

\section{THE CONSORTIUM}

European partners were selected according to their e-learning experience in the relevant areas of the project, their experience in the development of remote (distance monitoring and controlling of technical equipment) or virtual laboratories.

The four European partners are:

- The University of Limoges (UNILIM), coordinator of the project. In 2008 UNILIM launched a French-spoken blended learning ARTICC master [14] concerning electronics and optics topics, in parallel with the development of the "LAB-EN-VI" [9];

- The Katholieke Universiteit Leuven (KU Leuven), expert in the field of embedded systems and with a good experience in e-learning, particularly in the development of online remote laboratories [11];

- The School of Engineering of the Polytechnic Institute of Porto with expertise in the development of remote laboratories [12]; 
- The University Polytehnica of Bucharest (UPB) with experience in the development of virtual laboratories, with emphasis on Physics, Mathematics and Computer Science.

Regarding the North African partners' institutions, it was attempted to ensure a good distribution map to better cover the territories, to integrate isolated universities and consequently to maximize the impact of the project. The idea was to involve also partners with no experience in these fields to ensure an efficient knowledge transfer.

From Algeria:

- The Abdelhamid Ibn Badis University, Mostaganem, coinitiator of the EOLES project, already involved in a joint diploma accreditation process for the ARTICC master [14] and with a large experience in e-learning and remote laboratories;

- The University of Guelma, host of the Centre for Research in Embedded Systems and Robotic (CReSER);

- The University of Adrar;

- The University of Batna.

FromTunisia:

- The University of Kairouan that launched a full e-learning curriculum in project management in 2010;

- The Tunis Virtual University, responsible for coordinating e-learning development in the whole country;

- The University of Sfax;

- The ISET Sousse.

From Morocco:

- The Cadi Ayyad University, Marrakech;

- The Abdelmalek Essaâdi University, Tétouan;

- The Sultan Moulay Slimane University, Béni Mellal.

\section{ACKNOWLEDGEMENTS}

Authors wish to thank to all the administrative, technical and pedagogical teams working on this project for their support.

\section{REFERENCES}

[1] "Degrees and courses for international students." Internet: www.openuniversity.edu [Oct. 29, 2013]
[2] Jinwen Zhu, "A hybrid online-education strategy for delivering engineering and technology courses," Proc. 2nd International Conference on Networking and Digital Society (ICNDS'2010), Vol. 2, 2010, pp. 448-451.

[3] "Bachelor of Science in Electrical Engineering - How Online Degrees Work." Internet:

distance.und.edu/degree/about/?id=electricalengbs\&page $=791$ [Oct. 29, 2013]

[4] "Bachelor of Science in Engineering Technology: Electrical $(2+2$ program).” Internet:

distanceed.uncc.edu/programs/engineering/bachelor-scienceengineering-technology-electrical [Oct. 29, 2013]

[5] M. M. Albu,, K. E. Holbert, G. T. Heydt, S. Dan Grigorescu, V. Truşcă, "Embedding Remote Experimentation in Power Engineering Education," IEEE Trans. on Power Systems, Vol. 19, No. 1, February 2004, pp. 139-143.

[6] D. Hercog, B. Gergič, S. Uran, K. Jezernik, "A DSP-Based Remote Control Laboratory," IEEE Trans. on Industrial Electronics, Vol. 54, No. 6, December 2007, pp. 3057-3068.

[7] M. T. Restivo, J. Mendes, A. M. Lopes, C. M. Silva, F. Chouzal, “A Remote Laboratory in Engineering Measurement", IEEE Trans. on Industrial Electronics, Vol. 56, No. 12, December 2009, pp. 4836-4843.

[8] J. García-Zubia, I. Angulo, J. Irurzun, P. Orduña, J. Ruiz, U. Hernández, M. Castro and E. Sancristobal, "Easily Integrable Platform for the Deployment of a Remote Laboratory for Microcontrollers", International Journal of Online Engineering, Vol. 6, Issue 3, August 2010, pp. 26-31.

[9] A. Cardoso, P. Gil, "Online Learning in Engineering Courses Using Wireless Sensor and Actuator Networks", International Journal of Engineering Pedagogy, Vol. 3, Special Issue 1, February 2013, pp. 7680 .

[10] S. Farah, A. Benachenhou, G. Neveux, D. Barataud, "Design of a Flexible Hardware Interface for Multiple Remote Electronic Practical Experiments of Virtual Laboratory", International Journal of Online Engineering, Vol. 8, Special Issue 2, March 2012, pp. 7-12.

[11] F. Priem, R. De Craemer, J. Calu, F. Pedreschi, T. Zimmer, S. Saïghi, J. Lilja, "E-Learning in Science and Technology via a Common Learning Platform in a Lifelong Learning Project," European Journal of Open, Distance and E-Learning, No.1, March 2011, 24 pp.

[12] N. Sousa, G. R. Alves, M Gericota, "An Integrated Reusable Remote Laboratory to Complement Electronics Teaching," IEEE Transactions on Learning Technologies, Vol. 3, No. 3, July-September 2010, pp. 265 271.

[13] Fang-Fang Chua, Eng-Soon Tay, "Developing Virtual Learning Environment 2.0 Using Web Services Approach," Proc. 12th IEEE International Conference on Advanced Learning Technologies (ICALT'2012), July 2012, pp.230-234.

[14] "Master ARTICC." Internet: www.sciences.unilim.fr/formation/discipline/physique/master-articc [Oct. 30, 2013]

This project has been funded with support from the European Commission. This publication reflects the views only of the authors, and the Commission cannot be held responsible for any use which may be made of the information contained therein. 